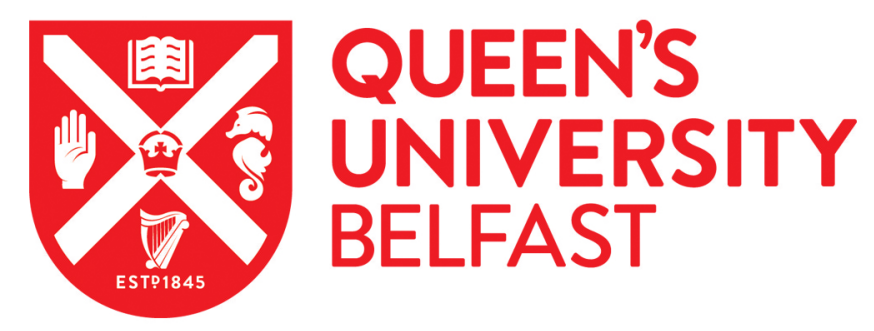

\title{
Complex arts-based interventions for patients receiving haemodialysis: A realist review
}

Carswell, C., Reid, J., Walsh, I., McAneney, H., Lee, J. B., \& Noble, H. (2020). Complex arts-based interventions for patients receiving haemodialysis: A realist review: A realist review. Arts and Health.

https://doi.org/10.1080/17533015.2020.1744173, https://doi.org/10.1080/17533015.2020.1744173

\section{Published in:}

Arts and Health

\section{Document Version:}

Peer reviewed version

Queen's University Belfast - Research Portal:

Link to publication record in Queen's University Belfast Research Portal

\section{Publisher rights}

Copyright 2020 Taylor and Francis. This work is made available online in accordance with the publisher's policies. Please refer to any applicable terms of use of the publisher.

\section{General rights}

Copyright for the publications made accessible via the Queen's University Belfast Research Portal is retained by the author(s) and / or other copyright owners and it is a condition of accessing these publications that users recognise and abide by the legal requirements associated with these rights.

Take down policy

The Research Portal is Queen's institutional repository that provides access to Queen's research output. Every effort has been made to ensure that content in the Research Portal does not infringe any person's rights, or applicable UK laws. If you discover content in the Research Portal that you believe breaches copyright or violates any law, please contact openaccess@qub.ac.uk. 


\begin{abstract}
Background: Many patients who develop end stage kidney disease require haemodialysis, a treatment that requires attending hospital three times a week for four hours each visit. This treatment impacts profoundly on quality of life (QoL) and mental health. Arts-based interventions for patients receiving haemodialysis could help address the impact of this treatment; however there is a lack of consensus on the methods of implementation and the mechanisms of these interventions in specific clinical contexts. Methods: Using a realist approach, relevant articles were synthesised to inform theory relating to the mechanism and implementation of complex arts-based interventions for patients receiving haemodialysis. Results: The theoretical framework includes two implementation phases, firstly one to one delivery of person-centred arts activities during haemodialysis and secondly, display of completed artwork within the unit. This intervention triggers mechanisms such as flow, social capital and an aesthetic experience. Implementation is hindered by the constraints of the haemodialysis unit and patients lack of confidence in their artistic skills. The impacts of these issues are reduced by a flexible approach to implementation, patient's desire to pass time and support from healthcare professionals.
\end{abstract}

\title{
Keywords
}

Arts-based intervention, arts in medicine, haemodialysis, arts in health, end-stage kidney disease,

Realist synthesis 


\section{Background}

End-stage kidney disease (ESKD) is the final stage of chronic kidney disease and is reached when a person's kidneys are close to failing or have already failed, meaning their estimated glomerular filtration rate is below $15 \mathrm{ml} / \mathrm{min}$ per $1.73 \mathrm{~m}^{2}$. (Bauer, Melamed, \& Hostetter, 2008). Patients with ESKD experience difficult symptoms including fatigue, pruritus, pain, nausea, sexual dysfunction and muscle weakness, which can profoundly impact quality of life (QoL) (Raj, Ahuja, Frandsen, \& Jose, 2017). In addition to these challenging symptoms, patients also face a demanding treatment regimen. The primary treatment modalities for ESKD are renal replacement therapies (RRT), with haemodialysis being the most common first established treatment modality (Byrne et al., 2018). Haemodialysis is a timeconsuming treatment that requires attendance at hospital three times a week for up to four hours each visit. During treatment, the patient is connected to a dialysing unit that filters their blood and removes waste products and excess fluid; replacing the role of the kidneys. Haemodialysis requires that patients attend regular, frequent and lengthy haemodialysis sessions, maintain a strict diet, restrict their fluid intake and take prescribed medications. Adhering to this strict regimen is not only important in reducing morbidity and mortality, but is also needed to manage symptoms. Symptom burden has a profoundly negative impact on the health related QoL of patients with ESKD (Davison \& Jhangri, 2010), and an increase in symptom burden is associated with an increase in depression (Wan Zukiman, Yaakup, Zakaria, \& Shah, 2017). Due to the complex interplay of QoL, depression and symptom burden in patients with ESKD receiving haemodialysis, urgent attention and a holistic approach to care is indicated.

Arts-based interventions involve the implementation of arts activities in a healthcare context to deliver a creative experience (Centre for Arts in Medicine, 2017), and could potentially be used to improve the QoL and healthcare experiences of patients receiving haemodialysis. The use of arts-based interventions in healthcare stems from the premise that engagement in the arts has a beneficial impact on health and wellbeing (Davies, Knuiman, \& Rosenberg, 2015), and that arts engagement can therefore be conceptualised as an important determinant of health, similar to diet and exercise (BMA, 2011). 
Research has explored implementation of arts-based interventions in a variety of healthcare settings, including medical-surgical units (Sonke et al., 2015) and primary care (Crone et al., 2012). Studies examining the impact of arts-based interventions in mental health settings report improvements in selfesteem, cognitive function, anxiety, stress and QoL (Leckey, 2011). A number of reviews have shown arts-based interventions can reduce anxiety, stress, pain and depression in patients in a variety of healthcare settings (Boyce, Bungay, Munn-Giddings, \& Wilson, 2017; Bungay, Munn-Giddigs, \& Wilson, 2014; Rosalia Staricoff \& Clift, 2011). However, these reviews are too broad in scope and lack specificity in relation to the targeted population and the context in which the intervention is delivered, important considerations in any complex healthcare intervention. Additionally, these reviews do not summarise the necessary components of arts-based interventions required to improve outcomes for patients, or explore how to replicate these interventions in different clinical contexts. While arts-based interventions could help address the difficulties patients with ESKD experience when receiving a demanding treatment such as haemodialysis, the current literature base fails to explore how arts-based interventions work in different clinical contexts, how the context can influence the outcome of the interventions, the essential components underlying successfully implementation of these interventions, nor how to replicate these interventions for the purpose of rigorous evaluation.

\section{Defining arts-based interventions}

The term 'arts' encompasses practices that appear fundamentally different to each other, in that they involve different sensory modalities and skills, for example music and painting. To distinguish between different art forms and activities in health research, it is necessary to provide a classification of the 'arts'.

A review conducted by Bungay et al. (2014) highlighted the inconsistencies in classifying arts. Definition depends on factors chosen for demarcation; this can be artistic medium, sector, or mode of participation. In the review they classified arts based on the Arts Council England, (2013). Bungay et al. (2014) used five categories: visual and performing arts, music, dance, theatre and literature. In the referenced policy (Arts Council England, 2013) these categories are descriptive examples of activities 
included in their remit; they are not presented as classifications in themselves. Previously Arts Council England outlined seven areas of arts in their policy, these include combined arts, dance, interdisciplinary arts, literature, music, theatre and visual arts (Arts Council England, 2006). These classifications are determined by the focus of the policy, not a developed classification system.

Evidence-based classifications have been developed for the purpose of health research. Davies et al., (2012) acknowledged the inconsistencies in defining arts within the literature. They conducted an online survey, sampling 57 international experts in the field of art or arts in health, to develop a definition of arts engagement. Five classifications of art forms were defined: performing arts, visual arts, design and craft, literature, online, digital and electronic arts, and community and cultural festivals, fairs and events. A factor analysis of the identified arts engagement activities identified two dominant factors; active or receptive engagement. Active engagement was defined as creating art, while receptive engagement is observing or listening to the arts. This taxonomy is acknowledges both artistic medium and level of engagement as important factors in arts research (Davies et al., 2012). This enables health research not only to examine the effectiveness of particular arts forms, but examine how different levels of engagement can impact patients.

There also remains a lack of clarity in health research literature when defining arts-based interventions. This results from a lack of consensus on whether arts therapies (such as psychodrama, music therapy, art psychotherapy) are distinct from arts-based interventions (such as arts-in-medicine programmes, arts-based public health promotion). Arts therapies use art in the delivery of a psychological therapy to address issues such as depression and anxiety, and support mental and physical rehabilitation. All arts activities undertaken by arts therapists are conducted within a therapeutic framework (Health \& Care Professions Council, 2009). Some literature views arts therapies as arts-based interventions ( Heenan, 2006; Staricoff and Clift, 2011; Fancourt, 2017;), however other research highlights a need for distinction ( Sonke, 2015; Centre for Arts in Medicine, 2017).

The difference in professional requirements and licensing is cited as the primary need for a distinction to be made between these fields (Sonke, 2017). Art therapists are required to register with a regulatory 
body to ensure they meet standards of proficiency - in the UK this is the Health \& Care Professions Council. In the UK 'Art therapist' is a protected title, as is drama therapist, music therapist and art psychotherapist (Health \& Care Professions Council, 2009). There are currently no such regulations for people facilitating arts-based interventions.

Another justification for distinguishing between the fields is the fact people participate in art in their everyday lives, without any clinical or therapeutic objective, and this participation can contribute to improved health and wellbeing (Davies, et al., 2014). A review by Bungay et al. (2014) made a distinction between arts therapies (such as music therapy, drama therapy and art therapy) and participatory arts (such as music listening, painting, visual art viewing) as arts therapies place the primary focus on the therapeutic relationship, as opposed to creative activity. Research by Davies et al. (2012) made the same argument, stating that division is necessary as arts can influence health and quality of life without being a therapy. Sonke (2017) argued that artists and arts therapists have different scopes of practice, rendering the roles unique.

The difference in scope of practice between arts therapists and artists was highlighted by Sonke (2017). Arts therapists are members of the multidisciplinary clinical team and provide a clinical treatment. The treatment involves an initial assessment and ongoing evaluation of the patient to ensure treatment goals are achieved (Scope et al., 2017). A review by Bungay et al. (2014) made a distinction between arts therapies (such as music therapy, drama therapy and art therapy) and participatory arts (such as music listening, painting, visual art viewing) as arts therapies place the primary focus on the therapeutic relationship, as opposed to creative activity. Research by Davies et al. (2012) made the same argument, stating that division is necessary as arts can influence health and quality of life without being a therapy. Sonke (2017) argued that artists and arts therapists have different scopes of practice, rendering the roles unique.

Due to the differences in professional requirements and treatment goals for arts therapies and arts-based interventions, arts therapies (including art therapy, drama therapy, art psychotherapy and music therapy) will be excluded from this review. 


\section{Realist review}

Certain genres of arts-based interventions meet the Medical Research Council's description of a complex intervention (Medical Research Council, 2009), involving multiple interacting components, flexibility of the intervention, lack of clarity surrounding underlying mechanisms that lead to improved outcomes, and tailoring of implementation to context. Haemodialysis units present a unique clinical context likely to provide numerous barriers to the implementation of complex arts-based interventions, including practical considerations such as the maintenance of vascular access and more complex considerations in the form of cultural norms. Patients receiving haemodialysis are also a unique population, with higher rates of frailty and co-morbidity compared to the general population, undergoing an intensive, challenging and time-consuming invasive treatment (Gomez et al., 2015; Takeuchi et al., 2018)

Realist reviews take into consideration the context, mechanism and outcome to inform 'what works for whom under what circumstances, and why'(Wong, Greenhalgh, Westhorp, Buckingham, \& Pawson, 2013). Realist evaluation posits that an intervention changes the context within which it is implemented, for those who are acting within that context. These actors include not only the intended recipients of an intervention, but also those implementing the intervention and working or living within the context (Rycroft-Malone et al., 2012). Consequently realist reviews help develop more insightful and pragmatic conclusions in comparison to other forms of literature review (Rycroft-Malone et al., 2012). These issues have not been explored in previous literature reviews on arts-based interventions (Boyce et al., 2017; Bungay et al., 2014; R Staricoff, 2004; Rosalia Staricoff \& Clift, 2011), and therefore there is little guidance in the literature on what arts-based interventions work in the haemodialysis context, for whom they work and why they work. Due to the unique context of implementation, the complexity of arts-based interventions and the capacity of arts-based interventions to have unintended consequences for those working within a clinical environment (Wilson, Bungay, Munn-Giddings, \& Boyce, 2015), a 
realist review was identified as the best approach to understand the implementation of arts-based interventions within the haemodialysis context and to identify potential mechanisms that could produce beneficial outcomes.

A realist review was therefore conducted to identify existing theories underpinning arts-based interventions, identify key components and mechanisms of action, and understand the influence of context on their implementation. It answered the following questions:

1. What are the key components of arts-based interventions that facilitate or hinder their implementation within a haemodialysis context?

2. Which contextual factors help or hinder implementation of arts-based interventions?

3. What mechanisms are triggered that allow the arts to act as a supportive intervention for patients receiving haemodialysis?

\section{Methods}

\section{Scoping the literature}

An initial background search was conducted to explore the existing literature base on arts-based interventions in healthcare settings to identify key issues and theories in arts in health. During this initial exploration it was apparent that there was a significant gap in the empirical literature evaluating artsbased interventions in the haemodialysis setting. After consultation with stakeholders, including academics and practitioners in the field of arts in health, it was decided to explore healthcare settings and populations which were thought to have similar contextual issues to haemodialysis units. Artsbased interventions for adult patients receiving bone marrow transplants were identified due to similarities in clinical setting and symptom profile of patients. However, following a review of the empirical literature in this context (Carswell, Reid, Walsh, \& Noble, 2018) the patient population and context were determined to be less transferable than originally thought and restricting the scope of the 
realist review to patients receiving haemodialysis would be the most effective way of answering the review questions.

\section{Search methods for the review}

The electronic databases Cochrane Database of Systematic Reviews, MEDLINE, PsycINFO, Embase, CINAHL, web of science, and Scopus were searched from their conception to January, 2018. Due to the scope of the review and the lack of available empirical evidence, no time parameters were placed on the search and a broad search strategy used search terms focused on the population and the intervention. The search terms were developed from reviewing the search strategies of existing systematic literature reviews on similar interventions (Bradt, Dileo, Magill, \& Teague, 2016; Bradt, Shim, \& Goodill, 2015; Deshmukh, Holmes, \& Cardno, 2014) or patient groups (Rabindranath et al., 2005). The search string for the population and the intervention were combined with the Boolean operator AND to create the final strategy. An example of this strategy can be seen in Table 1 for MEDLINE and which was adapted for all other databases.

Realist reviews draw on a broad range of literature to inform the relationship between mechanisms, context and implementation, including charity reports, programme evaluations, guidelines, news articles and editorial articles (Wong et al., 2013). Grey literature was included by searching databases such as the British Library of E-Theses Online (ETHOS), Canadian Agency for Drugs and Technologies in Health (CADTH), and the NHS Economic Evaluation Database. Reports from noted arts in health charities were also searched, including artsandhealth.ie, National Alliance for Arts, Health and Wellbeing and Arts Council England.

In total this strategy identified 5,883 articles across all electronic databases for review. Relevant journals were identified by reviewing the selected journals from relevant systematic literature reviews focused on similar interventions, such as dance therapy (Bradt et al., 2015), music therapy (Bradt et al., 2016), and art therapy (Hertrampf \& Warja, 2017; Ruddy, Milnes, Ruddy, \& Milnes, 2008), and these journals 
archives were searched individually. The reference and citation lists for included articles were searched individually to ensure all relevant literature was included in the review.

\section{Selection and appraisal of articles}

Articles were assessed for inclusion on the basis of their contribution to both theory and understanding of implementation of complex arts-based interventions within a haemodialysis context. This resulted in both empirical and non-empirical articles being included, in order to secure a comprehensive overview of potential underlying mechanisms that might contribute to the outcomes of complex arts-based interventions. The term 'art therapy' and art therapy journals had been included in the search strategy because the lack of distinction in the literature between arts-based interventions and art therapy results in the potential for articles on arts-based interventions to be indexed under 'art therapy'. Therefore it was necessary to understand the components of an intervention before determining whether or not it should be classed as an 'art therapy' or an arts-based intervention. Articles were therefore excluded during screening if the intervention met the definition of art therapy. Articles were also excluded if the intervention contained additional components that may contribute to the underlying mechanism, such as mindfulness or exercise. Articles where the participants were under the age of 18, or where the intervention was administered outside the haemodialysis setting, were excluded due to differences in context and population. A full overview of inclusion and exclusion criteria are provided in Table 2.

Articles were included if the intervention was assessed as highly complex according to the 'intervention Complexity Assessment Tool for Systematic Reviews' (iCAT-SR), as realist reviews have been specifically recommended for the evaluation of complex interventions (Lewin et al., 2017). Empirical articles were critically appraised using the Joanne Briggs Critical Appraisal Tool (The Joanna Briggs Institute, 2017) for quasi-experimental studies and qualitative studies, and the Mixed Methods Appraisal Tool (MMAT) (Nha hong et al., 2018) and were classified in terms of rigor as strong, moderate or weak. The JBI critical appraisal tools were selected as they provided a structured critical appraisal process for a variety of methodologies, whilst the MMAT provided a structured critical 
appraisal process for specifically for mixed-methods studies. Whilst the critical appraisal process enabled identification of methodological issues in the limited empirical literature, the appraisal was not used to guide inclusion or exclusion of articles. No articles were excluded based on the rigor of the methodology, as those that were either non-empirical or weak in rigor contributed to the understanding of programme theories relating to underlying mechanisms and the relationship between context and implementation.

\section{Data extraction}

Data were extracted using a previously published data extraction form for realist reviews (Morton et al., 2018; O'Halloran, Scott, Reid, \& Porter, 2015). A comprehensive data extraction form was used to identify important information relating to the realist synthesis of the included articles and can be seen in Table 3. This form extracted the results of empirical studies or evaluations to identify underlying mechanisms and the contextual issues that act as barriers or facilitators to implementation, therefore editorial articles were not included in this table. This extraction form was based on RAMESES publication standards for realist synthesis (Wong et al., 2013).

\section{Identification of candidate theories}

A realist synthesis aims to identify, articulate and examine underlying programme theories and assess whether these theories are relevant and applicable to the existing evidence base (Rycroft-Malone et al., 2012). Candidate theories were identified during preliminary scoping of the literature and were discussed and reviewed with all members of the research team. These theories were built upon during close reading of the included articles. Explicit theories that informed intervention development and implementation were identified and implicit theories were assumed from components of the interventions, whilst explanatory accounts of mechanism and context were identified from editorial articles. Factors that helped or hindered implementation were identified to better inform the synthesis of candidate theories in relation to the context of haemodialysis. 


\section{Synthesis of candidate theories}

Each paper was read, critically appraised and assessed individually, the components of the data extraction table were compared and synthesised in combination with the explanatory accounts generated from editorial articles, and grouped into discrete themes relating to mechanism (M), context (C), outcome (O) and intervention (I). The utility of candidate theories were discussed and reflected upon in relation to these themes within the literature by all members of the research team, and discussed with stakeholders who comprised the larger study's interdisciplinary advisory group (Carswell, Reid, Walsh, McAneney, \& Noble, 2019). Finally the theories were pulled together into a context + mechanism $=$ outcome $(\mathrm{CMO})$ configuration to elucidate how and why complex arts-based interventions may be successfully implemented and improve outcomes within a haemodialysis context (Rycroft-Malone et al., 2012).

\section{Results}

Study selection

The screening and selection process for articles is documented in Figure 1. The search resulted in 4,746 hits after duplicates were removed. Due to the deliberately broad scope of the search and the inclusion of the term 'art' in the search strategy, the majority of titles identified in the initial database search were irrelevant. However, removal of the term 'art' was considered too limiting, and priority was given to sensitivity over specificity of the search strategy due to the dearth of available empirical literautre identified during the scoping stage.

After screening titles, 88 articles were identified for screening of abstracts. On the basis of the abstract 44 were excluded; a total of 44 articles remained for screening of full texts. During full text screening five articles were identified that had English abstracts but were published in non-English languages (Korean, Portuguese, Japanese and Arabic). Attempts were made to source a translation service through the university library or language centre but this service was not available, so these articles were 
excluded. Full text screening resulted in 19 articles being excluded. Reasons for exclusion during the screening process are documented in Figure 1. The interventions described in the remaining articles were assessed for the level of complexity by the iCAT-SR (Lewin et al., 2017) to ensure that the included empirical articles utilised complex interventions and therefore had similar relevance to context and uncertainty surrounding mechanism. From this assessment, 14 articles were deemed to include simple interventions and were excluded. In total, 11 articles were included in this review; including three peer-reviewed empirical articles (Corrigan et al., 2017; Ross, Hollen, \& Fitzgerald, 2006; Rowe et al., 2011), one formal evaluation from an arts in health charity (Moss, 2012), one guideline on establishing arts in health practices (Field, 2007), three news articles on completed arts in health projects (Anam Beo, 2012; Galway University Hospitals Arts Trust, 2013; Haiku Island Press, 2016), and three editorial articles (Butt, 2016a; Curtis, Tanner, \& Cullen, 2011; Tanner, 2013). Figure 1 provides an overview of the screening and selection process. Table 4 provides a brief summary of the characteristics of included articles according to the RAMESES publication guidelines (Wong et al., 2013).

\section{Study characteristics}

The three empirical articles used different methodological designs. One used an observational design (Ross et al., 2006), one was a phenomological study (Rowe et al., 2011), and one was a mixed-methods evaluation (Corrigan et al., 2017). Five articles contained programme evaluations, although three of these were news articles that provided only a brief description of evaluation processes (Anam Beo, 2012; Galway University Hospitals Arts Trust, 2013; Haiku Island Press, 2016).

\section{Methodological quality}

The three peer reviewed empirical articles were of differing quality. The mixed-methods evaluation by Corrigan at al., (2017) was assessed as low quality according to the MMAT (Nha hong et al., 2018). The remaining two empirical studies were assessed using the Joanna Briggs Institute critical appraisal tools (The Joanna Briggs Institute, 2017); the observational study by Ross et al. (2006) was assessed as moderate; the qualitative study by Rowe et al. (2011) was assessed as strong. 


\section{Main objectives of the studies}

Only one of the studies sought to evaluate the impact of a complex arts-based intervention for patients receiving haemodialysis (Ross et al., 2006). Other objectives were primarily descriptive, either aiming to explore patient experiences of arts in medicine (AIM) programmes (Corrigan et al., 2017; Rowe et al., 2011), to explore artists perceptions of AIM programmes (Field, 2007) or to describe current AIM projects and practice (Field, 2007; Moss, 2012).

\section{Study populations}

The majority of the articles described haemodialysis units in Ireland, while two were located in the USA and one in England. One empirical study collected data from healthcare professionals (nurses) working on a haemodialysis unit (Corrigan et al., 2017).

\section{Complex arts-based interventions}

All empirical articles explored the use of AIM programmes within haemodialysis units. AIM programmes involve the implementation of different art forms within the medical environment by a professional artist (Sonke et al., 2015; Sonke, Rollins, Brandman, \& Graham-Pole, 2009). The programmes identified in this review are not a standardised intervention and do not involve a single artistic undertaking, but instead involve the provision of regular active arts activities throughout the hospital, with ongoing input from the artist alongside patients and staff. The AIM programmes involved numerous and variform mediums and projects. These programmes focus on the art forms and mediums used, the descriptions ranging from 'visual arts' (Corrigan et al., 2017) to a list of different options including crafts, creative writing, playing music and painting (Ross et al., 2006).

\section{Candidate theories}


None of the articles described an explicit theory underlying the implementation and development of the AIM programme, although one article identified explicit theories that informed understanding of patient experiences of an AIM programme:

This absorption allowed them to 'forget the machine', 'pass the time' or to 'take you out of thinking about yourself'. One patient spoke about being 'caught up' in the activity. These experiences of being 'caught up' are reminiscent of Mihaly Csikszentmihalyi's (2008) concept of 'flow', a state of absorption in which people describe time passing much faster, becoming less conscious of self, and having a sense of control over what they are doing.(Rowe et al., 2011, p.67)

In order to induce a flow state, a person must be engaged in an activity that is challenging, whilst they develop the requisite skills to meet that challenge. Curtis et al. (2011) highlighted the need for skill development and increasing complexity of arts activities over time within AIM programmes (Curtis et al., 2011). Most articles described subjective experiences of flow as the main benefits of the programmes, particularly the phenomenon of tachypsychia, with the experience of time passing quicker (Anam Beo, 2012; Curtis et al., 2011; Moss, 2012; Ross et al., 2006).

What I am now doing eats up dialysis time - I am always thinking, composing and battling to get new words out. (Tanner, 2013)

While engaging in flow states is thought to enhance a person's subjective sense of wellbeing, the ability to speed up time whilst on haemodialysis is a particularly attractive prospect in this arena, where time is often perceived as a burden (Moran, Scott, \& Darbyshire, 2009).

Rowe et al. (2011) also identified the enhancement of social interaction between patients, healthcare professionals and families as a potential mechanism for the benefits seen in arts-based interventions. This enhanced social interaction and development of social networks was identified as an underlying 
mechanism of impact in other articles (Corrigan et al., 2017; Moss, 2012), and social engagement was actively encouraged in described interventions by involving both healthcare professionals and families in the development of art projects (Field, 2007), displaying artwork in communal areas (Curtis et al., 2011) , implementing group projects that can be collectively contributed to (Anam Beo, 2012) and coordinating shifts to ensure that patients participating in the arts could attend at the same time (Moss, 2012). This provides patients, healthcare professionals and families with a shared experience, particularly one that is separate to disease and ill health (Galway University Hospitals Arts Trust, 2013). These experiences can build social capital and address the isolation patients may feel whilst on haemodialysis (Rowe et al., 2011).

The art also proved a great introductory way to get to know the patients on the unit. It was clear to see how the art helped the sense of community spirit. It made connections with people in separate beds and got them talking and discussing their different pieces.(Field, 2007, p.10)

An additional candidate theory relates to the clinical environment itself and how this is transformed by the arts. This may operate in a number of ways; by identifying creative opportunities available within the clinical environment (Butt, 2016b); by transforming the atmosphere within the unit from exclusively clinical to a more humanised creative setting (Field, 2007); and by addressing patient's aesthetic needs as part of holistic healthcare (Corrigan et al., 2017).

The background noise would recede and I would be transported briefly into a spiritual place of beautiful images and worlds, immense and far away. (Curtis et al., 2011, p.10)

Aesthetic deprivation is thought to be a common experience within the healthcare setting and may have a detrimental impact on wellbeing (Moss, 2012). By displaying artwork within a clinical setting and having active art engagement ongoing within a haemodialysis unit, the experience of aesthetic deprivation can be reduced in an attempt at enhancing the wellbeing of both patients and healthcare professionals. 


\section{Contextual factors that help or hinder implementation of complex arts-based interventions}

The issue of time on haemodialysis is well established in relation to how it can negatively impact on a patient's QoL and wellbeing (Gullick, Monaro, \& Stewart, 2017), and consequently time may be one of the most significant contextual factors that help implementation of arts-based interventions. As patients attend hospital three times a week for a period of four hours each visit, during which time they have limited opportunity for meaningful activity (Tanner, 2013), patients can experience 'existential boredom' (Moran et al., 2009) and have a desire to be occupied. This provides patients with a strong motivation to participate in AIM programmes despite a lack of previous interest in arts, something unique to the haemodialysis context (Rowe et al., 2011).

AIM programmes were implemented by an artist in residence who provided arts activities at the bedside of haemodialysis patients during their treatment. The provision of an artist was thought to be essential for implementation, with the guidelines advising that an undergraduate degree in art is necessary for any artist working within a hospital setting (Field, 2007). In programmes where more than one artist was involved in implementation consistent communication using log books ensured consistency across sessions (Ross et al., 2006). The provision of a flexible person-centred approach was identified as helping implementation of the interventions. Providing a variety of choice of art activities ensured patient interest could be sustained (Curtis et al., 2011), and the tailoring of the activities to patient needs, such as patients with visual impairment, meant all patients had the opportunity to participate (Ross et al., 2006). Consistent feedback and encouragement to patients by the artist was also identified as a core component of implementation, with a need to focus on continual skills development (Curtis et al., 2011).

Buy in from staff and collaboration with healthcare professionals was identified as helping implementation within the clinical setting (Anam Beo, 2012; Curtis et al., 2011). This ensured practical 
support for the artist to navigate the clinical setting as well as providing opportunities for organisational adaptation to facilitate implementation, such as changing patient shift patterns to enable those interested to attend sessions together (Curtis et al., 2011; Moss, 2012). A lack of prior experience of art amongst patients and lack of familiarity of arts in health amongst healthcare professionals was seen as hindering initial implementation and resulted in a protracted period of integration within clinical practice (Galway University Hospitals Arts Trust, 2013). Capacity to change was evident amongst all described projects, and this was facilitated by the practical consideration the artists gave to the environment to ensure the arts activities did not interfere with clinical practice (Ross et al., 2006). Feedback was encouraged from both the patients and healthcare professionals within these units, with regular evaluations of these programmes ensuring the needs of participants would be prioritised (Corrigan et al., 2017; Moss, 2012). Evaluation of these programmes revealed positive attitudes from healthcare professionals in relation to arts programmes with the belief that these interventions should be implemented in additional clinical settings.

The majority of arts in medicine programmes were externally funded or implemented by an external organisation - typically an arts in health charity. This may result in the sustained availability of the intervention becoming precarious, as it is dependent on consistent external funding (after contacting an author of one of the articles it was discovered the programme was no longer running due to loss of funding). However, the external sourcing of resources and staff reduces the burden placed on the haemodialysis unit.

Factors identified as hindering implementation included apprehension experienced by patients and their perceived lack of self-belief in their artistic abilities. This was effectively addressed in most articles by consistent encouragement, support, and constructive feedback from the facilitator (Curtis et al., 2011; Tanner, 2013). Display of completed artwork also acted as a way to reduce patient apprehension around the prospect of completing art on dialysis, by showing direct examples of work that have been completed by peers. Unpleasant treatment procedures and symptoms experienced by patients may also hinder implementation, as fatigue and pain can reduce patient's ability or willingness to engage in arts activities whilst on haemodialysis (Anam Beo, 2012). Establishing a relationship with the artist was 
seen as an essential component to implementation, with the acknowledgement that this process required time and a flexible, relaxed approach from the facilitator (Field, 2007).

\section{Synthesis of candidate theories}

In this section the intervention (I), mechanism (M), contexts (C) that are thought to produce the outcome (O) of improved wellbeing, mental health and QoL, will be identified from the information currently available in the literature, with the aim of explaining and supporting future implementation. The theoretical model can be seen in Figure 2.

Implementation of complex arts-based interventions appeared to consistently involve two implementation phases:

Firstly, the facilitated, individual art session patients engage in during haemodialysis with an artist. During this time they are supported to learn new artistic skills and provided with consistent, constructive feedback on their work $\left(\mathrm{I}^{1}\right)$. This helps induce subjective experiences characteristic of a flow state for and within the participant, which transforms their perception of time, allowing them to feel a sense of accomplishment and control (M).

Secondly, the artwork produced by patients is collected and displayed the clinical setting $\left(\mathrm{I}^{2}\right)$. While this also promotes a sense of accomplishment for the participant, it more importantly develops social capital by providing patients with a shared experience in their participation and collaboration in an arts project; simultaneously addressing the issue of aesthetic deprivation by transforming the clinical environment $(\mathrm{M})$. These mechanisms are thought to result in reduced anxiety and depression, enhanced QoL, and an overall improved experience of haemodialysis treatment $(\mathrm{O})$.

Implementation may be hindered by a number of contextual issues, such as the practical considerations of the clinical environment with restricted room and mobility of participants, the symptoms and difficulties associated with haemodialysis treatment, as well as an unfamiliarity with, and apprehension 
about, engaging in arts activities (C-). However, implementation can be facilitated by support from healthcare professionals working in the unit, the desire of patients to pass time whilst on haemodialysis and embedding arts into the culture of the renal unit by consistent implementation over a prolonged period of time $(\mathrm{C}+)$.

The lack of randomised controlled trials and predominant focus on exploratory designs and programme evaluation results in a lack of clarity surrounding the intended outcomes (O) of AIM programmes. While there is a suggestion that AIM programmes may improve depression and QoL amongst patients receiving haemodialysis (Ross et al., 2006) future research is needed in this area to determine the effectiveness of these interventions.

Overall, arts-based interventions may lead to improved outcomes for patients receiving haemodialysis through the inducement of a subjective experience characteristic of a flow state, the promotion of social capital and the reduction of aesthetic deprivation, but rigorous research is needed to establish their effectiveness in this context.

\section{Discussion}

This realist review firstly highlights the paucity of literature available in this area, as no randomised controlled trials or quasi-experimental studies were identified that evaluated the impact of complex artsbased interventions for patients receiving haemodialysis. The majority of evidence synthesised in this realist review were published reports of established AIM programmes from notable arts in health charities, while only three articles were sourced from peer-reviewed journals. This reflects a dearth of randomised controlled trials for complex and active arts-based interventions, regardless of context of implementation or target population (Boyce et al., 2017; Bungay et al., 2014).

Despite the lack of evidence that establishes the effectiveness of arts-based interventions, the available literature did provide an insight into the underlying theory, potential mechanisms and contextual factors that inform the success of implementation. The components of the interventions and the subjective 
experiences of patients who participated provided some insight into how these interventions may work in a haemodialysis context. The inducement of subjective experiences characteristic of a flow state, the promotion of social capital with both patients and healthcare professionals and the reduction of aesthetic deprivation all could contribute to improved outcomes.

While a number of components were identified that either helped or hindered implementation, it is the interaction of context and mechanism in the case of complex arts-based interventions that may help explain the successful implementation of the described programmes. In relation to the context of the haemodialysis unit, time on dialysis appears to strongly influence both successful implementation of a programme as well as the potential activation and benefits of the experiences associated with flow. The need to engage in meaningful activity during the protracted periods of time on dialysis provides a contextually unique motivator, while the desire for time to pass quickly during treatment could help reinforce the benefits of the subjective experiences of a flow state. While other factors can hinder implementation, such as the realities of a clinical environment, difficult symptoms, and the challenging treatment process, the support from healthcare professionals and a flexible approach to facilitation ensured that these barriers could be overcome.

\section{$5 \quad$ Strengths and limitations}

This is the first realist review to contribute to the development a theoretical framework for implementation of a complex arts-based intervention for patients receiving haemodialysis, including the components necessary for implementation and the underlying mechanisms that may contribute to outcomes. However, this review did not contain any clinical trials or impact studies, and therefore no conclusions can be drawn on the effectiveness of complex arts-based interventions at improving clinical outcomes in patients receiving haemodialysis. The grey literature and editorial articles included in this study provided important insight into underlying mechanisms, but little guidance on how to implement these interventions within a randomised controlled trial framework. Additionally only one article 
collected data from healthcare professionals, therefore there is limited insight into how the interaction between intervention, mechanism and context impact on professionals.

There is a significant need for randomised controlled trials looking at the effectiveness of complex artsbased interventions for patients receiving haemodialysis. Future research should also consider the experiences of healthcare professionals during implementation of complex arts-based interventions, to ensure all relevant contextual factors are identified to enable long-term clinical implementation. While experiences of engaging in AIM programmes are highly positive from both the perspective of patients and healthcare professionals, most of the identified programmes were externally sourced and provided by voluntary organisations reliant on public funding. Therefore the lack of rigorous evidence on the impact of these interventions can limit the ability to justify funding and prevent patients from accessing a resource that has the potential to improve QoL.

\section{Conclusion and recommendations}

In conclusion, this review contributes to the development of a theoretical framework that can inform implementation of complex arts-based interventions within haemodialysis units. However the lack of rigorous research assessing the effectiveness of these interventions limits the ability to evaluate their outcomes. This realist review elucidates underlying mechanisms and important contextual factors that can inform future randomised controlled trials. It is recommended that future research focuses on developing a robust evidence base, which in turn can justify the sustainable provision of complex artsbased interventions for patients receiving haemodialysis.

\section{Funding}

No funding was obtained to conduct this review. The review informed a larger study where funding was obtained from Northern Ireland Kidney Patient Association and Kidney Care UK to purchase items for an arts-based intervention. 


\section{References}

Anam Beo. (2012). Sanctuary. Retrieved February 25, 2019, from http://www.artsandhealth.ie/casestudies/sanctuary/

Arts Council England. (2006). Arts policies, 1-12. Retrieved from http://www.artscouncil.org.uk/media/uploads/downloads/dance_policy.pdf

Arts Council England. (2013). Great art and culture for everyone. Manchester, United Kingdom.

Bauer, C., Melamed, M. L., \& Hostetter, T. H. (2008). Staging of Chronic Kidney Disease: Time for a Course Correction: Table 1. Journal of the American Society of Nephrology, 19(5), 844-846. https://doi.org/10.1681/asn.2008010110

BMA. (2011). The psychological and social needs of patients. London. Retrieved from http://www.ahsw.org.uk/userfiles/Other_Resources/Health_Social_Care_Wellbeing/psychologi calsocialneedsofpatients_tcm41-202964_copy.pdf

Boyce, M., Bungay, H., Munn-Giddings, C., \& Wilson, C. (2017). The impact of the arts in healthcare on patients and service users: A critical review. Health and Social Care in the Community, 1-16. https://doi.org/10.1111/hsc.12502

Bradt, J., Dileo, C., Magill, L., \& Teague, A. (2016). Music interventions for improving psychological and physical outcomes in cancer patients. The Cochrane Database of Systematic Reviews, (8), CD006911. https://doi.org/https://dx.doi.org/10.1002/14651858.CD006911.pub3

Bradt, J., Shim, M., \& Goodill, S. W. (2015). Dance/movement therapy for improving psychological and physical outcomes in cancer patients. The Cochrane Database of Systematic Reviews, (1), 1-43. https://doi.org/https://dx.doi.org/10.1002/14651858.CD007103.pub3 
Bungay, H., Munn-Giddigs, C., \& Wilson, C. (2014). The Value of the Arts in Therapeutic and Clinical Interventions : A critical review of the literature. Cambridge.

Butt, C. A. (2016a). Art in my veins: A medical self-portrait. JAMA, 316(16), 1628-1629. https://doi.org/https://dx.doi.org/10.1001/jama.2016.15507

Butt, C. A. (2016b). Art in My Veins. JAMA, 316(16), 1628-1629. https://doi.org/10.1001/jama.2016.15507

Byrne, C., Caskey, F., Castledine, C., Davenport, A., Dawnay, A., Fraser, S., ... Williams, A. J. (2018). The UK Renal Registry 20th Annual Report. Retrieved from https://www.renalreg.org/wp-content/uploads/2018/06/20th-Annual-Report_web_book.pdf

Carswell, C., Reid, J., Walsh, I., McAneney, H., \& Noble, H. (2019). Implementing an arts-based intervention for patients with end-stage kidney disease whilst receiving haemodialysis: a feasibility study protocol. Pilot and Feasibility Studies, 5(1), 1-11. https://doi.org/10.1186/s40814-018-0389-y

Carswell, C., Reid, J., Walsh, I., \& Noble, H. (2018). Arts-based interventions for hospitalised patients with cancer: a systematic literature review. British Journal of Healthcare Management, 24(October), 611-616.

Centre for Arts in Medicine. (2017). Talking about Arts in Health: A white paper addressing the language used to describe the discipline from a higher education perspective, 1-24. Retrieved from http://arts.ufl.edu/site/assets/files/106496/uf_cam_language_whitepaper.pdf

Corrigan, C., Peterson, L., McVeigh, C., Lavin, P., Mellotte, G., Baker Kerrigan, A., ... O’neill, D. (2017). The perception of art among patients and staff on a renal dialysis unit. Irish Medical Journal, 110(9), 633. Retrieved from http://imj.ie/the-perception-of-art-among-patients-andstaff-on-a-renal-dialysis-unit/

Crone, D. M., O’Connell, E. E., Tyson, P. J., Clark-Stone, F., Opher, S., \& James, D. V. B. (2012). It 
helps me make sense of the world: The role of an art intervention for promoting health and wellbeing in primary care-perspectives of patients, health professionals and artists. Journal of Public Health (Germany), 20(5), 519-524. https://doi.org/10.1007/s10389-012-0495-x

Curtis, F., Tanner, J., \& Cullen, P. (2011). Beyond Captured Time. Cork: Waterford Healing Arts Trust.

Davies, C., Knuiman, M., \& Rosenberg, M. (2015). The art of being mentally healthy: a study to quantify the relationship between recreational arts engagement and mental well-being in the general population. BMC Public Health, 16(1), 15. https://doi.org/10.1186/s12889-015-2672-7

Davies, C., Knuiman, M., Wright, P., \& Rosenberg, M. (2014). The art of being healthy: a qualitative study to develop a thematic framework for understanding the relationship between health and the arts. BMJ Open, 4(4), e004790. https://doi.org/10.1136/bmjopen-2014-004790

Davies, C., Rosenberg, M., Knuiman, M., Ferguson, R., Pikora, T., \& Slatter, N. (2012). Defining arts engagement for population-based health research: Art forms, activities and level of engagement. Arts and Health, 4(3), 203-216. https://doi.org/10.1080/17533015.2012.656201

Davison, S. N., \& Jhangri, G. S. (2010). Impact of pain and symptom burden on the health-related quality of life of hemodialysis patients. Journal of Pain and Symptom Management, 39(3), 477485. https://doi.org/10.1016/j.jpainsymman.2009.08.008

Deshmukh, S. R., Holmes, J., \& Cardno, A. (2014). Art therapy for people with dementia (Protocol). Cochrane Database of Systematic Reviews, (4), 9. https://doi.org/10.1002/14651858

Dileo, C., \& Bradt, J. (2009). On creating the discipline, profession, and evidence in the field of arts and healthcare. Arts \& Health, 1(2), 168-182. https://doi.org/10.1080/17533010903046984

Fancourt, D. (2017). Arts in health : designing and researching interventions. Oxford: Oxford University Press.

Field, G. (2007). The benefit of therapeutic art sessions for patients in a renal dialysis unit: a guide to 
establishing art in acute hospital renal dialysis services. Dublin.

Galway University Hospitals Arts Trust. (2013). The Magician and the Swallow's Tale. Retrieved February 25, 2019, from http://www.artsandhealth.ie/case-studies/the-magician-and-theswallows-tale/

Gomez, A. T., Kiberd, B. A., Royston, J. P., Alfaadhel, T., Soroka, S. D., Hemmelgarn, B. R., \& Tennankore, K. K. (2015). Comorbidity burden at dialysis initiation and mortality: A cohort study. Canadian Journal of Kidney Health and Disease, 2(1), 1-9. https://doi.org/10.1186/s40697-015-0068-3

Gullick, J., Monaro, S., \& Stewart, G. (2017). Compartmentalising time and space: A phenomenological interpretation of the temporal experience of commencing haemodialysis. Journal of Clinical Nursing, 26(21-22), 3382-3395. https://doi.org/http://dx.doi.org/10.1111/jocn.13697

Haiku Island Press. (2016). Tiny, Kind Gestures. Retrieved February 25, 2019, from http://www.artsandhealth.ie/case-studies/tiny-kind-gestures/

Health \& Care Professions Council. (2009). What is an Arts therapist? Retrieved November 2, 2017, from http://www.hcpc-uk.co.uk/assets/documents/10004B66Arts-therapy.pdf

Heenan, D. (2006). Art as therapy: An effective way of promoting positive mental health? Disability and Society, 21(2), 179-191. https://doi.org/10.1080/09687590500498143

Hertrampf, R.-S., \& Warja, M. (2017). The effect of creative arts therapy and arts medicine on psychological outcomes in women with breast or gynecological cancer: A systematic review of arts-based interventions. Arts in Psychotherapy, 56, 93-110. https://doi.org/http://dx.doi.org/10.1016/j.aip.2017.08.001

Kelly, C. G., Cudney, S., \& Weinert, C. (2012). Use of creative arts as a complementary therapy by rural women coping with chronic illness. Journal of Holistic Nursing. 
https://doi.org/10.1177/0898010111423418

Leckey, J. (2011). The therapeutic effectiveness of creative activities on mental well-being: A systematic review of the literature. Journal of Psychiatric and Mental Health Nursing, 18(6), 501-509. https://doi.org/10.1111/j.1365-2850.2011.01693.x

Lewin, S., Hendry, M., Chandler, J., Oxman, A. D., Michie, S., Shepperd, S., ... Noyes, J. (2017). Assessing the complexity of interventions within systematic reviews: Development, content and use of a new tool (iCAT-SR). BMC Medical Research Methodology, 17(1), 1-13. https://doi.org/10.1186/s12874-017-0349-x

Medical Research Council. (2009). Developing and evaluating complex interventions: new guidance. Medical Research Council.

Moran, A., Scott, P. A., \& Darbyshire, P. (2009). Existential boredom: The experience of living on haemodialysis therapy. Medical Humanities, 35(2), 70-75. https://doi.org/10.1136/jmh.2009.001511

Morton, R., Norwood, K., O’Halloran, P., Noble, H., Fogarty, D., Murtagh, F., ... Maxwell, P. (2018). Advance Care Planning With Patients Who Have End-Stage Kidney Disease: A Systematic Realist Review. Journal of Pain and Symptom Management, 56(5), 795-807.e18. https://doi.org/10.1016/j.jpainsymman.2018.07.008

Moss, H. (2012). Punchestown kidney research fund progress report: Art programme in the dialysis unit 2011-2012. Dublin.

Nha hong, Q., Pluye, P., Fàbregues, S., Bartlett, G., Boardman, F., Cargo, M., ... Vedel, I. (2018). MIXED METHODS APPRAISAL TOOL (MMAT) VERSION 2018 User guide. Montreal. Retrieved from http://mixedmethodsappraisaltoolpublic.pbworks.com/

O’Halloran, P., Scott, D., Reid, J., \& Porter, S. (2015). Multimedia psychoeducational interventions to support patient self-care in degenerative conditions: A realist review. Palliative and Supportive 
Care, 13(5), 1473-1486. https://doi.org/10.1017/S1478951514001229

Rabindranath, K., Daly, C., Butler, J., Roderick, P., Wallace, S., \& Macleod, A. (2005). Psychosocial interventions for depression in dialysis patients. Cochrane Database of Systematic Reviews. Retrieved from http://search.ebscohost.com/login.aspx?direct=true \&db=jlh\&AN=105838342\&site=ehost-live

Raj, R., Ahuja, K. D. K., Frandsen, M., \& Jose, M. (2017). Symptoms and their recognition in adult haemodialysis patients: Interactions with quality of life. Nephrology, 22(3), 228-233. https://doi.org/10.1111/nep.12754

Reynolds, F., \& Vivat, B. (2010). Art-making and identity work: A qualitative study of women living with chronic fatigue syndrome/myalgic encephalomyelitis (CFS/ME). Arts \& Health, 2(1), 6780. https://doi.org/10.1080/17533010903495306

Ross, E. A., Hollen, T. L., \& Fitzgerald, B. M. (2006). Observational study of an Arts-in-Medicine program in an outpatient hemodialysis unit. American Journal of Kidney Diseases, 47(3), 462468. https://doi.org/10.1053/j.ajkd.2005.11.030

Rowe, N., Jones, C. H., Seeger, L., Greaves, G., Holman, C., \& Turner, H. (2011). Forgetting the machine : Patients' experiences of engaging in artwork while on renal dialysis. Journal of Applied Arts \& Health, 2(1), 57-72. https://doi.org/10.1386/jaah.2.1.57

Ruddy, R., Milnes, D., Ruddy, R., \& Milnes, D. (2008). Art therapy for schizophrenia or schizophrenia-like illnesses ( Review ). Cochrane Database of Systematic Reviews, (3), 4-6. https://doi.org/10.1002/14651858.CD003728.pub2.Copyright

Rycroft-Malone, J., DeCorby, K., Snelgrove-Clarke, E., Kent, B., Stetler, C. B., Titler, M., ... Schultz, A. (2012). Realist synthesis: illustrating the method for implementation research. Implementation Science, 7(1), 1-10. https://doi.org/10.1186/1748-5908-7-33

Scope, A., Uttley, L., \& Sutton, A. (2017). A qualitative systematic review of service user and service 
provider perspectives on the acceptability, relative benefits, and potential harms of art therapy for people with non-psychotic mental health disorders. Psychology and Psychotherapy: Theory, Research and Practice, 90(1), 25-43. https://doi.org/10.1111/papt.12093

Sonke, J. (2017). Nurse perceptions of artists as collaborators in interprofessional care teams. Healthcare, 5(50), 1-14. https://doi.org/10.3390/healthcare5030050

Sonke, J., Pesata, V., Arce, L., Carytsas, F. P., Zemina, K., \& Jokisch, C. (2015). The effects of artsin-medicine programming on the medical-surgical work environment. Arts and Health, 7(1), 2741. https://doi.org/10.1080/17533015.2014.966313

Sonke, J., Rollins, J., Brandman, R., \& Graham-Pole, J. (2009). The state of the arts in healthcare in the United States. Arts \& Health, 1(2), 107-135. https://doi.org/10.1080/17533010903031580

Staricoff, R. (2004). Arts in Health: A Review of the Medical Literature. London.

Staricoff, Rosalia, \& Clift, S. (2011). Arts and Music in Healthcare: An overview of the medical literature: 2004-2011. London.

Takeuchi, H., Uchida, H. A., Kakio, Y., Okuyama, Y., Okuyama, M., Umebayashi, R., ... Wada, J. (2018). The prevalence of frailty and its associated factors in Japanese hemodialysis patients. Aging and Disease, 9(2), 192-207. https://doi.org/10.14336/AD.2017.0429

Tanner, J. (2013). Crossword - a patient's reflection on the WHAT arts programme in the WRH Dialysis Unit. Retrieved February 25, 2019, from http://www.artsandhealth.ie/perspectives/crossword-a-patient's-perspective-on-the-what-artsprogramme-in-the-renal-dialysis-unit-of-waterford-regional-hospital/

The Joanna Briggs Institute. (2017). Critical Appraisal Tools. Retrieved January 15, 2018, from http://joannabriggs.org/research/critical-appraisal-tools.html

Wan Zukiman, W. Z. H., Yaakup, H., Zakaria, N. F., \& Shah, S. A. Bin. (2017). Symptom prevalence and the negative emotional states in end-stage renal disease patients with or without renal 
replacement rherapy: A cross-sectional analysis. Journal of Palliative Medicine, 20(10), $1127-$ 1134. https://doi.org/10.1089/jpm.2016.0450

Wilson, C., Bungay, H., Munn-Giddings, C., \& Boyce, M. (2015). Healthcare professionals' perceptions of the value and impact of the arts in healthcare settings: A critical review of the literature. International Journal of Nursing Studies, 56, 90-101.

https://doi.org/10.1016/j.ijnurstu.2015.11.003

Wong, G., Greenhalgh, T., Westhorp, G., Buckingham, J., \& Pawson, R. (2013). RAMESES publication standards: Realist syntheses. Journal of Advanced Nursing, 69(5), 1005-1022. https://doi.org/10.1111/jan.12095

\section{$\underline{\text { Disclosure Statement }}$}

The authors declare that they have no conflicts of interest. 